\title{
Conceito de doença e normatividade no pensamento de Ludwig Binswanger e Medard Boss ${ }^{1}$
}

Frank Töpfer ${ }^{2}$

\section{Resumo}

Ludwig Binswanger e Medard Boss entendem a doença mental como uma falha na norma. Essa falha deve ser diagnosticada a partir de uma medida intrínseca do indivíduo. Embora concordem ambos com esse ponto de vista, Boss renuncia à ideia de Binswanger do homem como subjetividade relacionada a si mesma. Isto traz consequências - examinadas por este artigo - à afirmação de não se julgar a condição de uma pessoa por medidas externas.

Palavras-chave: Conceito de doença; Normatividade; Daseinsanalyse; Antropologia.

\section{Concept of disease and normativity in the thought of Ludwig Binswanger and Medard Boss}

\begin{abstract}
L. Binswanger and M. Boss understand psychic disease as failure of a norm. This failure is to be diagnozed from an intrinsic measure of the individual. While Binswanger and Boss agree on this point, Boss gives up Binswanger's idea of man as self-relational subjectivity. This bears consequences to the claim of not to judge a person's condition by external measures.

Keywords: Concept of disease; Normativity; Daseinsanalysis; Anthropology.

\footnotetext{
1 Palestra ampliada, apresentada originalmente na Associção Brasileira de Daseinsanalyse, São Paulo, em maio de 2010. Agradecimentos a Alexander de Carvalho e Adrian Spremberg pela tradução.

${ }^{2}$ Universität Tübingen, Institut für Ethik und Geschichte der Medizin, Goethestrasse 6, D-72076 Tübingen, Alemanha. Email: frank.toepfer@uni-tuebingen.de
} 


\section{Introdução}

Na daseinsanalyse terapêutica, o pensamento da normatividade assume uma função central para a compreensão de doença. Todos os representantes da daseinsanalyse reclamam não usar, no emprego de conceitos normativos, nenhum ponto de vista externo, mas sim o Dasein humano individual a partir dele mesmo, de seu próprio sentido, de sua própria medida, para descrevê-lo e avaliá-lo. Nisso procedem eles fenomenologicamente. Seus dois representantes principais, Ludwig Binswanger e Medard Boss, recorrem a diferentes concepções antropológicas. Binswanger entende o humano, tendo como guia o Ser e Tempo de Heidegger, essencialmente como relação a si mesmo; Boss se distancia dessa compreensão: originalmente um aluno de Binswanger, ele entende o humano, guiado pelo Heidegger tardio, como dessubjetivado, como domínio da abertura para o surgir do ente. Isso o traz involuntariamente a uma proximidade sistemática com as ideias de uma naturalização do espírito, alardeadas por muitos neurocientistas, psicólogos, biólogos evolucionistas e filósofos.

No que se segue, gostaria de investigar a relação de compreensão de doença, normatividade e antropologia no pensamento de Ludwig Binswanger e Medard Boss. Com isso, mostrarei que a pretensão de compreender o Dasein apenas a partir de si mesmo, sem submetê-lo a um conceito de doença cuja norma lhe seja exterior, está atada a pressuposições antropológicas. Caso tais pressuposições não se realizem, a referida pretensão rui.

\section{I- Ludwig Binswanger: o si-mesmo como princípio}

\section{Conceitos normativos diferentes}

O psiquiatra suíço Ludwig Binswanger vê na determinação heideggeriana do Dasein humano como ser-no-mundo a fundamentação metódica e objetiva da pesquisa psicopatológica. Isso tanto em um aspecto objetivo, porque com isso "o ser do humano todo" (Binswanger, 1947, p. 202) é compreendido e a psiquiatria pode libertar-se da orientação de abstrações como "alma" ou "cérebro", quanto em um aspecto metodológico, porque a estrutura do ser-no-mundo dispõe uma orientação para a descrição do Dasein psiquicamente doente. $\mathrm{O}$ psiquiatra agora sabe a que ele tem de atentar: à 
espacialidade, exposição, coloração, consistência ou materialidade e sensibilização do "projeto de mundo" (Binswanger, 1947, p. 202). A constituição do projeto de mundo se correlaciona com a constituição particular do Dasein. Com ele se dá imediatamente, de um modo determinado, um mundo composto: um horizonte universal de compreensão, dentro do qual todo comportar-se simplesmente tem sentido. Não há nenhum Dasein sem mundo. Mundo tem, consequentemente, status transcendental-apriorístico: porque não há nenhum comportar-se em relação a algo, nem mesmo a mim, sem já haver o conhecimento do todo de significância que o envolve. Este todo de significância é condição de possibilidade do comportar-se.

Decisivo para a qualificação do conceito de ser-no-mundo para a fundamentação metodológica da psiquiatria é a interpretação de Binswanger do ser-no-mundo enquanto norma. A partir dela desvios dever-se-iam deixar diagnosticar exatamente e cientificamente (vide Binswanger, 1947, p. 202). A orientação para a descrição dos projetos de mundo, ou seja, dos modos de serno-mundo, precisa ser normativa, porque Binswanger parte do conceito normativo de doença da clínica psiquiátrica. A explicação de tal conceito é um dos objetivos da aspiração de Binswanger, que é fundar a psiquiatria teoreticamente na daseinsaanalítica de Heidegger. Em seu centro, Binswanger vê o conceito de sintoma psicopatológico. O sintoma psicopatológico é resultado de um processo de redução diagnóstica. Nela formas uniformes do Dasein como mania ou esquizofrenia são deslindadas em sintomas: em funções psíquicas desordenadas. Elas são entendidas como expressão de perturbações de funções orgânicas fundamentais e, com isso, em princípio, como acessíveis a uma terapia causal biologicamente fundada. Ela é o objetivo da psiquiatria. De acordo com ela, a psiquiatria busca a "conexão com a biologia" (Binswanger, 1955, p. 297). Tal conexão se forma não apenas a partir da suposição de que as perturbações orgânicas seriam o motivo para as perturbações psíquicas, mas também enquanto o psíquico é concebido de acordo com o modelo da funcionalidade orgânica. As expressões médicas "saudável" e "doente" recebem seu sentido desse modelo. Trata-se, geralmente, também na psiquiatria, de "um objetivo ou julgamento de valor biológico, mensurado de acordo com a norma de integridade da capacidade e funções de um organismo" (Binswanger, 1955, p. 297). A doença psíquica é, daí, compreendida como fenômeno deficiente ou como privação.

Com este conceito de doença organológica funcional, impõe-se ao Dasein - como Binswanger entende - uma medida externa a sua compreensão de si. Tal conceito não se aplica ao homem, para o qual importa sua existência, seu modo de ser-no-mundo. Isso significa cometer um erro de categoria. A daseinsanalyse se inicia antes da redução diagnóstica: junto ao homem no todo 
de seu ser-no-mundo. Por isso se abstém dos conceitos psiquiátricos de saudável e doente, do mesmo modo que de todas as outras valorizações externas à compreensão de si do Dasein em questão (vide Binswanger, 1955, p. 288; 1957b, p. 17). Também a psiquiatria começa junto a um diagnóstico fenomenal precientífico (vide Binswanger, 1955, p. 282): um comportar-se esquisito, perturbações da comunicação cotidiana e similares. Ela, contudo, o faz irrefletidamente: sua medida precientífica é o "comportar-se médio do cidadão médio", sem que este seja propriamente investigado (Binswanger, 1933, p. 196). Doente é o que se afasta dele. Considerada antropologicamente, essa "forma de ser humano", porém, não tem nenhuma posição privilegiada. Ela é simplesmente a mais frequente (Binswanger, 1933, p. 198, 196). Esclaredendo o horizonte precientífico, no qual a psiquiatria se move - a explicação da norma “do comportar-se médio do cidadão médio" aí incluida (vide Binswanger, 1955, p. 216-217) -, a daseinsanalyse cumpre uma função fundamental para a psiquiatria.

Porém, se na descrição do Dasein psicótico e neurótico permanecem todas as avaliações fora do jogo, como pode então o ser-no-mundo servir como norma? A ideia de uma fundamentação da psiquiatria no conceito normativo de ser-no-mundo parece estar em desacordo com o abster-se de julgamentos avaliativos. Essa contradição se resolve com Binswanger meramente recusando todas as avaliações de fora, todos os "pontos de vista"; para o ser-no-mundo, porém, ele reclama que seja uma norma imanente que se dê com o próprio Dasein (vide Binswanger 1957a, p. 93). Interpretando Heidegger, Binswanger a vê no modo "autêntico" do ser-no-mundo, que tem sua contraparte no "inautêntico" (p. ex. Binswanger, 1933, p. 114 e 160; 1955, p. 307). Binswanger compreende autenticidade a partir da ética aristotélica enquanto vida bem sucedida ou felicidade. A vida se movimenta entre as possibilidades do sucesso e do malogro. A partir dessa noção, Binswanger vê dominada "toda a analítica existêncial do Dasein de Heidegger" (Binswanger 1956, p. X).

Enquanto formas do Dasein malogrado, Binswanger descreve as formas do ser humano nas quais a psicopatologia vê doenças psíquicas. Também a daseinsanalyse as compreende privativamente: enquanto "modi deficientes", nos quais momentos estruturais "falham", de tal modo que "lacunas" se abrem (Binswanger, 1957a, p. 12 e 19). O discurso acerca de "formas", contudo, sugere que o aspecto privativo não é o único. Se ele o fosse, só se poderia falar negativamente de destruição de formas, desvios e inconsistência de normas. Entretanto, na verdade, os desvios também apresentam algumas novas formas, modos do ser-no-mundo que se devem descrever positivamente. Com isso, apodera-se Binswanger do pensamento de Heidegger de que a "mundanidade", aquela estrutura que faz o mundo ao mundo, seja "modificável ao todo da estrutura de 'mundos' particulares" (Heidegger, 1927, p. 65). Mundo se torna, 
na interpretação de Binswanger desse pensamento, algo individual. Nos projetos de mundo individuais se funda a diversidade do Dasein humano (vide Binswanger, 1933, p. 25; 1947, p. 196 e 204), também - e isso é importante para o psiquiatra Binswanger - a diferença entre doentes psíquicos e saudáveis: não "sintomas" isolados, mas a estrutura total do ser-no-mundo os diferencia uns dos outros (vide Binswanger, 1955, p. 217, 255). Entre os modos individuais do ser-no-mundo, Binswanger reconhece sequências típicas, de modo que se possa falar, por exemplo, de um conceito daseinsanalítico da mania ou esquizofrenia e de um mundo específico do maníaco ou esquizofrênico (Binswanger, 1933, p. 89, 184; 1965, p. 20). Binswanger descreve esses tipos como "normas" (p. ex. Binswanger, 1947, p. 202) - normas com o sentido de que os modos de comportar-se e expressar-se de alguém psiquicamente doente obedecem a uma determinada composição de sentido e ordem. Todos esses tipos completam novamente a "norma" do ser-no-mundo geral na medida em que todos eles caem sob esse conceito.

"Norma" tem, em Binswanger, portanto, um sentido multifacetado: em primeiro lugar, um negativo, atuando o ser-no-mundo autêntico como norma para a constatação de desvios de algum Dasein malogrado; em segundo lugar, um positivo, pelo qual são reconhecíveis, nesses desvios, formas típicas de serno-mundo, composições de sentidos particulares cuja lógica rege toda forma de expressão e comportamento do dasein a que se refere (ou seja, de certa forma o normatiza) e em terceiro lugar, um outro positivo, atuando a estrutura do serno-mundo em geral como guia para a descrição de formas particulares típicas e individuais do ser-no-mundo. Norma é, no primeiro caso, o autêntico ser-nomundo. Nos segundo e terceiro, norma é a estrutura do ser-no-mundo enquanto tal. Apenas da primeira norma se pode desviar, apenas aí ocorre inconsistência da norma, violação da norma. Nos dois outros casos, a relação de norma e o que recai em seu campo de aplicação é de outro tipo. Binswanger a descreve não como desvio, mas como "variação" do ser-nomundo, conceito nem sempre conceitualmente diferenciado com clareza. Com "variação" não se diz uma alteração da estrutura fundamental do ser-nomundo (vide Binswanger, 1957b, p. 11). Por "variação" deve-se entender o sentido do arranjo, da organização individual concreta da estrutura idêntica do Dasein, através da qual as realizações dos Dasein de humanos individuais se diferenciam. Essas mudanças apresentam, por seu turno, diferentes configurações típicas - mania, esquizofrenia etc. 


\section{O conceito prático de norma de Binswanger: autenticidade enquanto Dasein bem-sucedido}

Dos três sentidos que norma tem em Binswanger, apenas o primeiro, norma no sentido do autêntico ser-no-mundo, com o auxílio do qual o doente psíquico enquanto desvio pode ser entendido, é relevante para o problema de um emprego prático-normativo do conceito de doença. Nos outros dois casos, trata-se de conceitos descritivos; sua denominação como "norma" é, por isso, equivocada.

Com o conceito prático de norma, Binswanger quer apropriar-se do conceito heideggeriano de autenticidade. Sua contraparte, a inautenticidade, não é, para Heidegger, entretanto, nenhum sinal de um comportar-se que se desvia da medianidade; ao contrário: inautenticidade é a normalidade. $\mathrm{O}$ conceito de inautenticidade não é, então, o equivalente daseinsanalítico do conceito psicopatológico de doença: inautenticidade caracteriza a medianidade, a doença psíquica é um desvio dela. Pode o conceito de inautenticidade, então, em geral, ser apropriado para a descrição psíquica do Dasein doente? Já não seria talvez o Dasein psiquicamente doente autêntico, porque não mediano? Para Binswanger, ele é inautêntico porque nele se encontra aquela característica especialmente marcada que Binswanger compreende como essência da inautenticidade. Ele reconhece "uma linha do perder-se existencial" do autêntico eu-mesmo, plenamente responsável, passando pelo inautêntico, relativamente irresponsável, "gente-mesmo" (Man-selbst) do Dasein cotidiano médio até ao “aparentemente (!) completamente 'irresponsável' e dependente 'impessoal'mesmo" ("'Es'-selbst") do Dasein doente psíquicamente. O princípio que domina essa sequência é o "princípio do si-mesmo" (Binswanger, 1933, p. 114). Inautenticidade significa perda de si mesmo, alienação de si mesmo; autenticidade, por sua vez, apropriação autêntica de si mesmo, "chegar a si mesmo" (vide Binswanger, 1933, p. 159, 178). O Dasein psiquicamente doente é o Dasein da alienação extrema de si mesmo. Aí o "ser decadente, no sentido de Heidegger, desempenha um papel determinante" (Binswanger, 1956, p. XII; 1957b, p. 28-29). Entretanto, este sentido de inautenticidade é ambíguo em Heidegger. Num sentido inofensivo reside uma inautenticidade no simples "ser junto ao mundo" (p. ex. Heidegger, 1927, p. 56), em cada comportar-se para com as coisas e os homens enquanto eu estiver me dedicando a eles e não refletindo sobre mim. O homem normal fraco pode, como Binswanger descreve, num ato de "meditação ('reflexão'), voltar a si mesmo" a qualquer momento (Binswanger, 1933, p. 167). Ele pode apropriar-se de si mesmo. A esse comportar-se para com o mundo e, por isso, no sentido inofensivo de inautenticidade e decadência, pertence também a mediação da relação ao 
mundo através da publicicade do "impessoal": dos anônimos outros. O impessoal abre ao Dasein em geral primeiramente um mundo, enquanto que apresenta perspectivas a ele. $\mathrm{O}$ impessoal diz para que algo é, para que se faz algo, põe à disposição modos possíveis de comportar-se, intermedeia conhecimentos e avaliações. Tudo isso se assume como evidente e isso possibilita o comportar-se no mundo. Por meio dessa aceitação, pertence-se ao impessoal e não há uma diferenciação pessoal. Contudo - normalmente -, assim como a partir da vivência do outro, é possível refletir sobre si mesmo e tornarse consciente de si como agente responsável, como indivíduo, cujo comportamento não é naturalmente determinado pelo impessoal, mas a que o indivíduo se relaciona e que pode escolher. Assim o indivíduo se diferencia em outras palavras, enquanto si-mesmo.

Para além do decair que se dá inevitavelmente com o ser dependente do mundo, Heidegger diagnostica, contudo, um interesse do Dasein em nãomeditar sobre si mesmo, um interesse já no decair, no perder-se. Segui-lo leva a um mais profundo estranhamento de si mesmo do que no "ser junto ao mundo" e não junto a si, porque se perde de vista a possibilidade de reconquistar-se saindo da entrega ao mundo rumo ao "poder ser si mesmo autêntico" (Heidegger, 1927, p. 322). Esse decair que se baseia em um interesse no perder-se não reside já no simples ser-dependente-do-mundo - uma impressão que as análises de Heidegger suscitam, porque ele, em toda ocasião, fala de decair sem nunca diferenciá-lo claramente, porque evidentemente toma ambos pelo mesmo.

Tem-se a ver, junto à doença psíquica, com o estranhamento de si mesmo que vai além do inofensivo decair no "ser junto ao mundo". Enquanto que Binswanger reconhece "uma linha" do perder-se do autêntico eu-mesmo até o inautêntico 'impessoal'-mesmo do Dasein psiquicamente doente, entende ele também a doença psíquica não como simples ocorrência, mas como movimento conduzido pelo interesse do Dasein: como "fuga" para a doença (Binswanger, 1933, p. 181). É, pelo menos em sua raiz, um comportar-se, do doente psiquico, como Binswanger acentua, apenas “aparentemente (!)" irresponsável por completo (Binwanger, 1933, p. 114; vide 163, 169). Diante do perder-se normal, Binswanger vê o doente psíquico distinguido pelo fato de o voltar a si da alienação de si não estar mais em poder deste humano. Por isso, precisa ele de auxílio psiquiátrico ou psicoterapêutico. O objetivo deste auxílio é, daseinsanaliticamente entendido, abrir novamente para o que sofre psiquicamente a possibilidade de voltar a si mesmo e, com isso, a possibilidade de uma vida feliz (vide Binwanger, 1955, p. 306f.; 1957a, p. 165; 1957b, p. 34).

Caso deva a terapia conduzir o doente de volta a seu "poder ser si mesmo autêntico", o que diferencia esse "autêntico" ou "próprio" do 
inautêntico ou não-próprio? (Binswanger, 1955, p. 307) Porque a daseinsanalyse quer fazer compreensíveis as doenças psíquicas como possibilidades postas na estrutura do Dasein humano, pode-se objetar que também elas pertencem às possibilidades de existência do humano em geral, sendo-lhe, portanto, próprias. Essa objeção é tanto mais plausível porque Binswanger compreende a doença psíquica em sua raiz como fuga, e não como ocorrência. É exatamente por isso que se poderia argumentar que o estar-doente psíquico não é nenhum caso de inautenticidade: com a escolha da fuga na doença, apropria-se o Dasein de uma possibilidade de sua existência.

Por que a doença psíquica, contudo, representa uma forma de inautenticidade? Chega-se perto de uma resposta, caso se pergunte de quê o Dasein foge caindo na doença. Assim como Binswanger faz com o estar-doente psíquico, Heidegger entende todo decair como fuga (Heidegger, 1989, p. 244). Foge-se da indeterminação que chega com a orientação para o futuro do Dasein próprio; foge-se da incerteza que aí reside, sustentando-se nos dados do impessoal e no presente do vivido no mundo (p. ex. Heidegger, 1927, p. 170; 1976, p. 228, 235; 1979, p. 425f.). Binswanger descreve a fuga na doença psíquica como fuga para a determinação. Suas análises encontram a todo momento um "degenerado", "encolhido", “encurtado”, uma estrutura de algum modo menos organizada, "empobrecida". Elas definem o Dasein "em um círculo de possibilidades determinadas que se torna cada vez menor" (Binswanger, 1957a, p. 104-105; vide 1933, p. 22-24, 161-162). E sempre mostra a interpretação temporal do estar-doente psíquico, que deve tornar compreensível este por fim, uma fixação no passado e no presente, portanto, na determinação, e um recuar da orientação para o futuro. O futuro parece já determinado, enquanto que ele é experienciado como dominado pelo passado (vide Binswanger, 1957a, p. 105, 119, 124). Quando o futuro, porém, com relação à experiência, tem grande peso, é porque ele não é articulado com o presente do doente. Trata-se de um futuro fantástico, que não conduz o doente a lugar algum, mas o deixa nas determinações em que ele está. Uma consequência disso é a limitação do "estar aberto para as possibilidades". Eis porque Binswanger pode formular como objetivo de uma psiquiatria e psicoterapia orientadas daseinsanaliticamente $o$ abrir novamente ao doente "o preenchimento de suas possibilidades de ser" (Binswanger, 1957b, p. 34). Com a fuga para a doença, um Dasein agarra de fato uma possibilidade de sua existência. Mas é a possibilidade do "fechar os olhos" (vide Heidegger 1989, p. 242) diante da constituição de ser própria: diante da temporalidade, indeterminação e incerteza da vida própria, agarra-se à possibilidade de negar a apropriação de si mesmo, a autenticidade.

O que isso significa para a pergunta sobre a normatividade do conceito de doença? A autenticidade de Heidegger significa uma relação consigo mesmo que principalmente se retira de toda percepção externa. A apropriação de si 
mesmo isola, enquanto ela me confronta com minha temporalidade e finalmente com minha morte que, afinal, só eu posso encontrar. Contanto que com a autenticidade uma norma se determine, ela só pode ter seu fundamento no Dasein individual. - Será que Heidegger entende a autenticidade normativamente? Não se pode responder essa pergunta univocamente por conta da ambiguidade que se mostrou no conceito da inautenticidade: inautenticidade significa para um o "ser junto ao mundo" que se posiciona necessariamente no comportar-se cotidiano e este significado não é normativo (vide Heidegger, 1927, p. 176, 179). E inautenticidade para outro significa a perda de si mesmo que vai além do ser junto ao mundo, para o qual um interesse em perder-se a si mesmo é o fundamento. Importante para o Dasein é a superação desta última inautenticidade, de acordo com Heidegger (vide Heidegger, 1976 , p. 232; 1979, p. 441; 1989, p. 243). Toda a retórica da análise da cotidianidade em Ser e Tempo transporta-se do pathos para a superação da perda de si mesmo. Por isso a autenticidade em Heidegger tem também sentido normativo. Binswanger se agarra a isso e o faz abertamente através da identificação da autenticidade com vida feliz. Com a felicidade traz ele, porém, para o jogo, uma norma que só pode ser imanente. Pois o que a felicidade significa para um Dasein individual só se determina a partir dele. Somente nele essa norma tem o fundamento de seu valor. Com isso não se diz que ela deveria junto a todo indivíduo parecer diferentemente: Binswanger quer dizer que um Dasein só é feliz se ele tiver vivido no fundamento do modo "dual" do Dasein, no fundamento do "amor" 3 . Contudo, o que é decisivo é que ele conhece com a felicidade uma instância imanente ao Dasein individual, na qual uma tal compreensão antropológica precisa ser confirmada, através da qual, entretanto, ela também pode ser refutada.

\section{II- Medard Boss: o ser humano enquanto "lugar de acontecimento para o que tem de ser"}

\section{Da relação de si mesmo para o "lugar de acontecimento"}

Medard Boss via-se inicialmente como um estudante de Binswanger. Seus primeiros trabalhos daseinsanalíticos seguem a linha de seu mestre. Isso muda quando ele, no final da $2^{\circ}$ Guerra Mundial, entrou em contato direto com

\footnotetext{
${ }^{3}$ Vide Binswanger (1942), no qual Binswanger se refere à filosofia do diálogo, especialmente Martin Buber.
} 
Heidegger, mas não de modo tão amplo que pontos em comum entre ele e Binswanger não tenham subsistido. Como Binswanger, Boss entende o estardoente psíquico (e estar-doente em geral) como deterioração de uma condição saudável, portanto, entende-o privativamente: doença é falta de saúde. A saúde é a realização imperturbada dos fundamentos do existir humano; a doença, a deterioração dessa realização, que Boss, como Binswanger, compreende como desvio da norma. A doença enquanto desvio só se pode entender a partir da condição saudável, da norma. Desenvolvam-se os fundamentos do existir humano, então desenvolve-se com isso a libertade do Dasein (Boss, 1971, p. 447; 1979 , p. 155-156, 295-298). Dizendo de outro modo, e mais perto do modo de expressão de Binswanger: na doença são perturbados modos do ser-no-mundo, porque a relação com o mundo é essencial para o Dasein humano. E isto também com a doença somática, porque - como deixa entender Boss - o Dasein inteiro em sua relação com o mundo é afetado por toda e qualquer doença. Doenças físicas são por isso apenas primariamente, mas não exclusivamente físicas; correspondentemente, isso vale para a doença psíquica. Boss pura e simplesmente nega qualquer diferenciação. A totalidade do Dasein entra em seu lugar (p. ex. Boss, 1971, p. 15, 431, 445, 483).

A diferença entre Boss e Binswanger se acentua na relação eu - mundo. Binswanger a entendeu, com Ser e Tempo, como um tipo de dialética: o eu ou o si-mesmo é essencialemente ser-no-mundo. Porém, com o perigo de se perder no mundo, precisa ganhar-se novamente na reflexão sobre si mesmo: precisa de diferenciar-se do mundo enquanto aquele que se comporta com ele e consigo mesmo. Em Boss é diferente: ele vê o fundamento do existir humano no fato de que o humano "ek-siste", isso quer dizer: ele se entrega "essencialmente e de corpo e alma" à sua relação com as coisas e os outros humanos do mundo. "[...] ele está total e originalmente sempre fora, junto às coisas e os outros humanos", que ele percebe e a quem ele responde (Boss, 1979, p. 155, vide 147; 1971, p. 445). Esta é exatamente a formulação que Binswanger - com Ser e Tempo - usa para a descrição da decadência, da inautenticidade, do perder-se a si mesmo e do fracasso do Dasein. O mundo, no qual o homem está referido às coisas e aos outros humanos, compreende Boss como "domínio da abertura" indispensável para a possibilidade de seu acontecimento. Ele se abre e permanece aberto através do homem. Porque essa abertura é condição de possibilidade do acontecimento do ente, Boss pode determinar mais fundamentalmente a essência do humano do que enquanto relação com as coisas e com os outros homens: o homem é a essência que possibilita o acesso ao ente, à medida que que ele mantém aberto o domínio de acontecimento deste. Nisso reside um principio fundamental de seu existir. Boss oscila entre duas noções: por um lado, deve um tal existir pressupor "um aberto, um livre, um iluminado em si mesmo e enquanto tal", "no qual a abertura constante do humano pode incidir" 
(Boss, 1971, p. 353). Por outro lado, ele identifica diretamente mundo e humano: o humano é ele mesmo o "lugar de acontecimento para o que tem de ser", mesmo "o aberto, livre, iluminado" (Boss, 1971, p. 353-354). Seja de um modo ou de outro, decisiva para Boss é a superação de uma "subjetividade" existente para si (vide p. ex. Boss, 1979, p. 148, nota F.T.), que se contrapõe aos objetos existentes para si, e isso parece acontecer com as duas noções. Pois o lugar de acontecimento, o aberto ou iluminado, o homem abre ou é ele mesmo, no que ele é puro poder-perceber do que lhe acomete e, em relação às significações do que lhe acomete, é puro ser-acessível (Boss, 1979, p. 297; vide 353). Não pode haver aqui nenhuma dialética do si-mesmo e mundo no sentido de um perderse a si mesmo no mundo e ganhar-se de volta a partir dele, pois a "simesmidade" (Boss, 1979, p. 297) não é de modo nenhum outra coisa que o poder entregar-se à relação particular com o ente.

A determinação da essência do humano de Boss mostra claramente a orientação no pensamento tardio de Heidegger, enquanto Binswanger se apoia exclusivamente no Ser e Tempo e no Da essência do fundamento de 1929. Também esses primeiros trabalhos foram explicitados por Heidegger a Boss no solo de sua filosofia posterior. Levando em conta a diferença entre a compreensão de saúde e doença de Boss e Binswanger, faz pleno sentido a reinterpretação do que em Ser e Tempo ainda podia ser entendido no sentido de um sujeito ou de uma subjetividade: o Dasein enquanto aquele que se comporta em todo comportar-se com o seu ser, o ser do Dasein enquanto reflexividade imanente, a noção de um si-mesmo próprio, que se ganha na distinção do mundo. Essa reinterpretação fica bem clara na resposta de Heidegger à pergunta de Boss: o que "propriamente significa a frase central em Ser e Tempo: 'Dasein é aquele ente, para o qual no seu ser o seu próprio ser importa'?" (Heidegger, 2006, p.204). Nas mais variadas respostas fica de fora toda a relação de si, não apenas aquela sobre o fantasma cartesiano de um sujeito supostamente sem mundo que existe para si: o Dasein é o "deter-se junto aos que vêm ao encontro", a "abertura para os que vêm ao encontro". "O quem consiste apenas, em cada momento, nos modos de comportar-se, nos quais eu agora estou" (Heidegger, 2006, p. 204). O Dasein é o "ficar absorvido por aquilo que o toca agora" (Heidegger, 2006, p. 206) no sentido de "'ter seu comportamento determinado por algo', como, por exemplo, quando se diz: ele se identifica totalmente com aquilo que o toca". Precisamente em tal entrega alguém existe "propriamente enquanto aquele que ele é" (Heidegger, 2006, p. 205).

Contudo, qual seria a alternativa para essa autenticidade? Não pode haver nenhuma. Uma diferença de autenticidade e inautenticidade não pode mais ser pensada se eu não sou nada fora do comportar-se momentâneo com os que vêm ao encontro, se não há além do comportar-se com os outros um 
comportar-se consigo mesmo constitutivo para o Dasein. Pois, apenas uma relação consigo mesmo permite determinar o que é próprio ou autêntico e o que é inautêntico. Sem isso, perde-se também a possibilidade de compreender a doença psíquica como inautenticidade no sentido de um perder-se a si mesmo ou de uma alienação de si mesmo. Falta então a diferença necessária para consigo mesmo, que repousa em um comportar-se consigo mesmo.

\section{Norma objetiva ou subjetiva?}

Boss entende a doença de todo tipo como restrição do poder perceber os que vêm ao encontro; como restrição do domínio da abertura do mundo. É esse encurtamento que torna doentios os encurtamentos na realização dos diferentes fundamentos do existir humano: espacialidade, temporalidade, disposição, corporalidade, ser uns com os outros, ser mortal. Se é isso doença e é doença a privação de saúde, então saudável é quem realiza a "possibilidade da essência do ser acessível" na "abertura normativa" (Boss, 1979, p. 362).

Onde é mostrado se o existir se realiza na abertura normativa? Onde se mostra a saúde e onde se mostra sua privação, a restrição contranormativa da abertura e, portanto doença? Binswanger havia entendido aquelas formas de existência, que no modo de consideração redutora da psicopatologia mostram uma sintomática doentia, como malogradas e, daí, via como formas extremas de inautenticidade. A medida da avaliação - a norma -, com isso, reside no indivíduo, em seu encontrar-se. Onde Boss a vê? Sua crítica à avaliação de doentes a partir de um ponto de vista objetivante faz esperar que ele, assim como Binswanger, veja a norma como imanente ao Dasein. Na verdade, sua resposta se mostra ambígua. Por um lado, acentua ele que a norma não deveria ser "nunca intercambiável com uma 'normalidade' no sentido do aparição da medianidade fática numericamente mais frequente". O cumprir da norma seria "antes compreendido como aquela realização de nosso existir no qual este, no cumprimento de suas possibilidades de comportar-se completamente, consegue realizar-se diante dos que vêm ao encontro dele" (Boss, 1966, p. 53). Todos os homens vivem - como Boss, ao contrário de Binswanger, afirma - "junto às mesmas coisas de uma mundo compartilhado", mas "cada um do seu modo único e particular" (Boss, 1966, p. 50). Por isso, torna-se válido deixar desenvolver-se o modo próprio individual de um humano, sua "natureza mais própria" (Boss, 1966, p. 46. vide 1971, p. 478). Isso dando certo, a existência é feliz (vide Boss 1966, p. 46, 52; 1979, p. 372). Isso não dando certo, dá-se um desdobramento meramente restrito e privativo. A norma para a doença e a saúde reside, portanto, no indivíduo. Com isso, Boss apresenta a máxima 
terapêutica, a de deixar a doente experimentar "na própria carne" a insuficiência de realização de sua própria existência, de acordo com sua norma própria (vide p. ex. Boss, 1971, p. 533, 537; 1979, p. 144).

Por outro lado, Boss vê, por exemplo, no daltonismo geneticamente condicionado, um acontecimento privativo: o daltônico "sofre" da impossibilidade de se referir à "significação de 'vermelho' e 'verde'. Por isso ele não pode responder ao vermelho e verde correspondentes ao caráter destes dados: "ele não pode adequadamente comportar-se" (Boss, 1971, p. 446). O pensamento de que ele não pode isso porque o vermelho e o verde para ele não são dados, por isso essa "significância" simplesmente não existe para ele e, por isso, não tem nenhum sentido falar de em um "relacionar-se inadequado", parece natural aqui. Porém, a norma, da qual o daltônico se desvia, não é nenhuma que precise ser imanente ao indivíduo. Ela se forma através "das possibilidades de comportar-se dadas normalmente a um humano" (Boss, 1971, p. 447). O "mediano" constrói a medida, e não apenas para a verificação de desvios físicos, mas também para a verificação de "limitações da execução de determinados modos específicos de comportar-se do mundo compartilhado circundante" (Boss, 1971, p. 449). Com isso, claramente entra em jogo um ponto de vista objetivo, e uma avaliação "de fora" acaba acontecendo. Boss não se mantém fiel a sua pretensão fenomenológica de ater-se apenas a como as coisas "a partir delas mesmas se mostram": ao daltônico não se mostram nem o vermelho nem o verde. Caso se deva atrelar alguma norma a vermelho e verde, então a existência dessas cores não se deixa demonstrar fenomenologicamente para o daltônico.

Um outro exemplo se encontra no que Boss descreve como "perversões sexuais". De acordo com seu entendimento privativo de doença, ele as compreende como "configurações privativas do amar humano". Elas são, portanto, "sempre referidas a este amar em sua configuração não perturbada e saudável" (Boss, 1979, p. 295) e apenas daí podem ser compreendidas, da "norma do amor" (Boss, 1966, p. 42). Em suas análises das perversões sexuais, Boss experimentou primeiramente o método daseinsanalítico-fenomenológico, que pretende ater-se à vivência imediata e real dos doentes. Porém, Boss abandona o método fenomenológico quando ele, com vista às causas do comportamento sexual contranormativo, afirma que há "pessoas esporadicamente homosexuais que conseguem criar uma realidade amorosa com um parceiro configurado fisicamente do mesmo sexo, para as quais a única restrição em relação à norma é o fato da impossibilidade de conseguirem procriar" (Boss, 1979, p. 307). Pois a sua descrição da homosexualidade "constitutional" não mostra em lugar nenhum que uma tal falta tenha sido vivida como própria. Aqui não se trabalha o sentido imanente de um 
acontecimento, mas novamente está colocada uma norma de fora. Deve-se supor que é a norma da média social, aquela que está em vigor "no interior de uma determinada sociedade" (Boss 1979, p. 295); possivelmente Boss a visse fundada antropologicamente.

No caso do daltonismo, Boss parece, no entanto, ainda aplicar uma outra medida enquanto humano médio: a "adequação objetiva" do comportamento: o daltônico não pode responder ao caráter dos dados vermelho e verde, ele não pode comportar-se adequadamente. Saudável é quem o pode. Esta ideia de adequação objetiva do comportar-se ganha em Boss um significado fundamental: a abertura para o poder vir ao encontro do ente: "não estamos por nossa própria conta. Ao contrário estamos [...] por isso requeridos a oferecer a tudo aquilo que tenha chegado à sua vigência e a seu ser o lugar de acontecimento que lhe é indispensável." Nisso "jaz o sentido do existir humano" (Boss, 1979, p. 354). A abertura para o que vem ao encontro no mundo não se reduz a um mero receber: ela significa abertura para um apelo e a capacidade de correspondê-lo respondendo-o (vide p. ex. Boss, 1971, p. 446; 1979 , p. 296). Caso o ser humano se constitua, porém, de nada além que estar em relação com as coisas e com os igualmente humanos, então o ser todo de um humano está sujeito ao apelo à resposta adequada. Boss vê a medida para isso evidentemente na constituição das coisas. Não apenas tal constituição, mas também o normativo, que fornece um comportamento determinado, parece pertencer independentemente às coisas, se ele for experienciado. De fato, Boss fala de "dados" e do "que vem ao encontro"; os exemplos do daltonismo e da homosexualidade mostram, porém, que não se trata de modo algum do dado em cada caso. As coisas fazem uma demanda normativa também, nas situações em que o traço de caráter normativo é inexperienciável em princípio para o indivíduo.

Como poderiam, visto que a demanda teria que se dirigir ao indivíduo? Apenas de tal modo que o apelo fosse experimentado por meio da mediação da “sociedade" (Boss, 1979, p. 295). “As coisas" não fazem nenhuma pretensão mas a sociedade espera determinados modos de comportamento no trato com elas. A medida é, portanto, ao contrário do que inicialmente aparentava, novamente o homem médio.

No caso do daltonismo e da homossexualidade constitucional, o indivíduo em questão não pode comportar-se do modo que Boss vê como adequado. Porém, Boss vê também a possibilidade de que não se queira comportar-se adequadamente: pertence à liberdade humana obedecer ou negar "o ser-tomado-em-reclamação enquanto lugar de acontecimento para o que tem de ser", o "sentido do existir humano" (Boss, 1979, p. 354). O pensamento de uma liberdade do comportamento desempenha um papel também em níveis 
menos fundamentais: doentes esquizofrênicos, por exemplo, devem se habilitar para decidirem eles mesmos o que deixar aproximar-se deles e de que modo eles querem responder ao que vem ao encontro; uma habilidade que eles perderam: "esquizofrênicos estão entregues desamparada e desconsoladamente à investida do ente [...]", eles perderam a liberdade e a autonomia e "foram retirados da sua própria essência, por meio do poderio que lhes aflige" (Boss, 1979, p. 364; vide 363, 367). Por outro lado, o saudável é capaz de "possibilidades de relação autônomas" (Boss, 1971, p. 533). Ele pode decidir quais relações ele quer estabelecer.

Porém, uma tal noção, a noção de um comportamento livre que escolhe e que decide com referência ao quê vem ao encontro, um poder chegar-se e um poder distanciar-se, no qual o próprio se diferencia do outro, é omitida pelas pressuposições antropológicas de Boss. Essa noção diz que o homem não é apenas o lugar de acontecimento do que se mostra de fato. Assim, se ele for apenas a pura abertura para o ente que acontece, um palco, sobre o qual se encena algo, então não haveria nenhuma diferença entre uma investida superior do ente a um Dasein doente, que foi retirado "de sua própria essência", e qualquer outro acontecimento: como pura abertura, o Dasein seria entregue a todo acontecimento, a todo encontro com homens e coisas do mesmo modo. Ele não teria nenhum próprio que se pusesse em relação com homens e coisas, ao mesmo tempo determinando a si mesmo. Do que Boss precisaria para sua noção de liberdade do comportamento para com o que vem ao encontro, sua noção de soberania da aproximação e distanciamento, sua noção de um próprio, o qual por meio da investida do ente, do outro, pode perder-se, seria uma teoria da subjetividade. Subjetividade no sentido de um comportar-se consigo mesmo e um diferenciar-se do mundo no qual o sujeito está. Exatamente uma tal teoria Boss expressamente rejeita e sua possibilidade é excluída por meio da determinação antropológica fundamental do ser humano enquanto pura abertura para o que vem ao encontro. Assim, coloca-se a noção de um próprio que se determina a si mesmo fora da construção da teoria antropológica de Boss. No entanto, quase exclusivamente fora de sua fundação teorético-antropológica se encontra essa noção formulada: no contexto no qual se trata da prática terapêutico-daseinsanalítica e de formas de doença específicas, como a esquizofrenia (vide Boss, 1971, p. 533, 538, 567; 1979, p. 367, 372).

É para mim importante acentuar que não falo aqui sobre a real prática terapêutica de Boss, mas sobre a teoria antropológica que, de acordo com Boss, fundamenta sua praxis. Sobre a real prática dele posso falar na verdade muito pouco. Um vídeo da biblioteca de Würzburg, Alemanha, com uma sessão de terapia dele deu-me a impressão de que estava inteiramente orientado para 
fazer com que o indivíduo ganhe liberdade, de que ele trata seu paciente inteiramente como Dasein que se relaciona para consigo mesmo. Assim, pareceme que, em Boss, repete-se o que ele, seguindo Binswanger, critica em Freud: a desconexão entre a antropologia - a metapsicologia de Freud - e o princípio da praxis terapêutica faticamente orientada para a conquista de liberdade (vide $\mathrm{p}$. ex. Boss, 1979, p. 7-10, 105-121, 145-160). Seguirei ainda um pouco mais o nexo entre antropologia e prática terapêutica no decorrer do texto (e peço ao leitor que não se esqueça do que foi dito).

\section{III- Dessubjetivação e prática terapêutica}

Entre médicos e psicoterapeutas parece reinar o consenso de que o homem entendido como sujeito, pessoa ou Dasein é o objeto autêntico do diagnóstico e da terapia, não um sistema funcional psíquico ou orgão físico. (Isso não precisa significar que a prática siga sempre essa visão). Essa compreensão está baseada na consideração antropológica de que o homem é essencialmente determinado pela relação consigo mesmo, e não apenas consigo mesmo enquanto ser vivo orgânico, mas sobretudo consigo mesmo enquanto essência formadora no modo como lida com sua própria vida. Esse é um pressuposto para que o homem, enquanto pessoa ou si-mesmo, esteja doente e que ele possa ter êxito ou fracassar em sua vida como si-mesmo. A norma para a obtenção de sucesso ou fracasso se constrói na relação pessoal consigo mesmo. Ela é, por isso, de natureza individual. Essa é a visão de Binswanger. Ela se torna ainda mais significativa, quando uma forma de terapia como a daseinsanalyse não tem apenas a ver com uma perspectiva médica determinada que tenha integrado o indivíduo no todo de seu modo de viver, mas quando a terapia tem a ver com a vida malograda em seu todo, medida pelo metro de seu possível sucesso.

Boss segue até certo ponto a visão de Binswanger da individualidade da norma da vida bem-sucedida. Ele, porém, não mantém algo: um palco para o acontecimento do ente pode apenas ser "doente" no sentido de que esse palco não cumpre uma função que não the tenha sido delegada por ele mesmo. Não há aqui nenhuma perspectiva interna, mas apenas um ponto de vista externo. A dessubjetivação do homem pretendida por Boss não permite mais pensar uma norma própria ao indivíduo para o sucesso e o fracasso. Com isso, Boss torceu a visão original em seu avesso: iniciada contra a objetivação do homem no acesso a uma medicina que se entende naturalcientificamente, permanece uma concepção que faz o homem ao reflexo dos acontecimentos anônimos. 
O que significa isso para o objetivo da terapia daseinsanalítica, para a conquista de liberdade, ou para a auto-determinação do indivíduo? Autodeterminação implica uma relação consigo mesmo. Esta é abandonada através da dessubjetivação do homem que a transforma em um local de meros acontecimentos anônimos. Essa quase-naturalização do humano traz Boss inadvertidamente para as proximidades de uma concepção que ele expressamente contesta: a do naturalismo e do programa de uma naturalização do espírito. Se, para Boss, o humano é o mero reflexo dos acontecimentos, um sujeito, com isso, dissolvido, esse mesmo sujeito se desmascara naturalisticamente como encenação de um titereiro que age por detrás do palco: o cérebro. Não podemos nos furtar a essa encenação, não podemos acabar com nossa autoexperiência de agir por uma decisão da vontade, não podemos nos livrar de nossa autoexperiência de essência consciente. Por isso vivemos em dois mundos, cujos modos de descrição se excluem mutuamente. Contudo, apenas um destes mundos é o propriamente real: o do cérebro. $\mathrm{O}$ do do sujeito agente, ao contrário, uma ilusão, se não for visto como o que é: construção do cérebro, epifenômeno sem efeito. O cérebro é a única causa de nossas pretensas decisões de agir. Correspondentemente, são-lhe atribuidas as propriedades pessoais conhecidas: O cérebro "planeja”, "arranja” e assim por diante ${ }^{4}$ É exatamente pelo fato do cérebro parecer tão humano que cabe à pesquisa neurológica (combinada à biologia evolucionista) tornar-se em nossa cultura o paradigma predominante da autosignificação humana: reconhecemo-nos nele novamente e cremos ter resolvido "em princípio" o enigma que somos para nosso próprio pensamento - consciência, vontade, sensação -, ao nos vermos como ilusão. Um reconhecimento de si próprio que não significa apropriação de si, mas alienação de si.

Boss vê claramente que se trata, na verdade, de metáforas antropomorfizantes com relação às supostas capacidades psíquicas do cérebro, seu planejar, arranjar etc., e que a subjetividade do cérebro é simulada através de um truque de linguagem (p. ex. Boss, 1971, p. 46). Ele reconhece a coisificação do humano que aí reside. O que Boss não vê, porém, é que sua opinião antropológica fundamental transforma o humano em uma coisa. Por isso as consequências são essencialmente as mesmas. Além disso, é muito importante o fato de que a reificação do homem e a simultânea desrealização do sujeito - i.e., do pessoal, do si mesmo - faz com que não seja mais aceitável defender racionalmente que uma essência determine (ao menos potencialmente) seu próprio comportamento - por exemplo, sua expressão linguística Mas se a auto-determinação do sujeito - não como exceção, mas como princípio - é ilusão, que tipo de comprometimento poderia ter, por exemplo, a autonomia do paciente e a obrigação ao respeito à constituição de

\footnotetext{
${ }^{4}$ Vide por exemplo Roth, 2003.
} 
vida que foi escolhida por ele mesmo? Cada decisão aparentemente autodeterminada seria verdadeiramente sempre algo diferente do que ela parece ser. Auto-determinação e ganho de liberdade seriam fundamentalmente ilusões. Só pode ser então irracional esclarecê-los como princípios terapêuticos. Não é possível se responsabilizar racionalmente, mantendo convicções e práxis de um mundo da vida cujo caráter ilusório é patente. Exatamente como através da dessubjetivação do determinismo natural, a autodeterminação do sujeito, da pessoa ou do Dasein, é teoreticamente - não necessariamente também na práxis efetiva -, abandonada através da concepção do homem como de um mero reflexo dos acontecimentos históricos.

\section{Referências bibliográficas}

Binswanger, L. (1933). Über Ideenflucht. Zürich: Orell Füssli.

(1942). Grundformen und Erkenntnis menschlichen Daseins. Zürich: Max Niehans.

(1947). Ausgewählte Vorträge und Aufsätze I. Zur phänomenologischen Anthropologie. Bern: Francke.

. (1955). Ausgewählte Vorträge und Aufsätze II. Zur Problematik der psychiatrischen Forschung und zum Problem der Psychiatrie. Bern: Fracke.

(1956). Drei Formen mißglückten Daseins. Verstiegenheit, Verschrobenheit, Maniriertheit. Tübingen: Niemeyer.

(1957a). Schizophrenie. Pfullingen: Neske.

. (1957b). Der Mensch in der Psychiatrie. Pfullingen: Neske.

. (1965). Wahn. Beiträge zu seiner phänomenologischen und daseinsanalytischen Erforschung. Pfullingen: Neske.

Boss, M. (1966). Sinn und Gehalt der sexuellen Perversionen. Ein daseinsanalytischer Beitrag zur Psychopathologie des Phänomens der Liebe. München: Kindler, sem ano (edição com licença da editora Hans Huber, Bern - Stuttgart).

. (1971). Grundriss der Medizin. Ansätze zu einer phänomenologischen Physiologie, Psychologie, Pathologie, Therapie und zu einer daseinsgemässen Präventiv-Medizin in der modernen Industrie-Gesellschaft. Bern - Stuttgart Wien: Hans Huber.

(1979). Von der Psychoanalyse zur Daseinsanalyse. Wege zu einem neuen Selbstverständnis. Wien - München - Zürich: Europaverlag. 
Heidegger, M. (1927). Sein und Zeit, Halle an der Saale: Niemeyer.

(1976). Logik. Die Frage nach der Wahrheit. Ed. W. Biemel. Frankfurt/Main: Vittorio Klostermann.

. (1979). Prolegomena zur Geschichte des Zeitbegriffs. Ed. P. Jäger, Frankfurt/Main: Vittorio Klostermann.

. (1989). Phänomenologische Interpretationen zu Aristoteles. Anzeige der hermeneutischen Situation. Ed. H.-U. Lessing. In: Dilthey-Jahrbuch 6.

. (2006). Zollikoner Seminare. Protokolle - Zwiegespräche - Briefe. Ed. M. Boss. Frankfurt/Main: Vittorio Klostermann, 3. Edição.

Roth, G. (2003). Aus Sicht des Gehirns. Frankfurt/Main: Suhrkamp. 